Article

\title{
Eco-Efficiency Trends and Decoupling Analysis of Environmental Pressures in Tianjin, China
}

\section{Zhe Wang ${ }^{1,2}$, Lin Zhao ${ }^{1, *}$, Guozhu Mao ${ }^{1}$ and Ben Wu ${ }^{3}$}

1 School of Environmental Science and Engineering, Tianjin University, Tianjin 300072, China; E-Mails:wmomo@mail.nankai.edu.cn (Z.W.); maoguozhu@tju.edu.cn (G.M.)

2 Department of Environmental Science and Engineering, Binhai College, Nankai University, Tianjin 300270, China

3 Tianjin Academy of Environmental Sciences, Tianjin 300191, China; E-Mail: wb_0118@126.com

* Author to whom correspondence should be addressed; E-Mail: zhaolin@tju.edu.cn;

Tel./Fax: +86-22-2789-2622.

Academic Editor: Vincenzo Torretta

Received: 17 September 2015 / Accepted: 12 November 2015 / Published: 19 November 2015

\begin{abstract}
This study analyzes Tianjin's eco-efficiency trends during the period 2001-2013 and reasons for their changes, with the aim of contributing to efforts to ensure the city's sustainable development. While eco-efficiency of all of the indicators that we analyzed showed improvements during the study period, a gap remained in comparison to the more advanced eco-efficiency observed both domestically and internationally. We subsequently introduced decoupling indices to examine the decoupling relationship between environmental pressure and economic growth. This analysis demonstrated that some progress occurred during the study period resulting from the implementation of existing policies and measures entailing resource conservation and reduction in the emission of pollutants. The latter applied, especially, to sulfur dioxide $\left(\mathrm{SO}_{2}\right)$ and chemical oxygen demand (COD), which both retained strong decoupling states from 2006 to 2013. Other indicators showed an apparent tendency toward decoupling, but most displayed weak decoupling. These findings indicate that further efforts are urgently required to promote strong decoupling. At the end of the twelfth Five-Year Plan period, Tianjin should consider formulating policies from the perspectives of resource consumption and pollutant emissions reduction to promote further sustainable development.
\end{abstract}

Keywords: eco-efficiency; decoupling analysis; sustainable development; Tianjin 


\section{Introduction}

In light of reforms and the opening up of its economy in 1978, China has been experiencing rapid economic development. While this process has propelled China into becoming the world's second largest economy, it has also been accompanied by a range of resource-related and environmental problems, such as depletion of water resources and extensive smog. The simultaneous occurrence of these critical issues creates bottlenecks that may affect future sustainable development (SD). The need to find efficient ways of balancing economic growth and environmental protection to pursue sustainability in China is, thus, a pressing issue for policymakers.

The concept of eco-efficiency, which has received considerable attention in the SD literature, is an approach that focuses on the relationship between the economy and the environment. In recent years, eco-efficiency strategies are frequently discussed as possible contributions to lower resource consumption and emissions while maintaining or increasing the value of economic output, namely, "decouple" resources use and waste emission from economic growth, and have been applied to industrial sectors, regions, and nations [1-7]. However, one recurrent criticism of eco-efficiency strategies is that the increase in efficiency can be subject to rebound effect, i.e., the efficiency improvements will increase rather than reduce consumption, which is also referred to as Jevons' paradox [8-10]. Currently, several organizations and academic groups has defined "decoupling", and a body of literature based on decoupling theory further extends evaluations of the relationship between environmental pressure and economic growth [11-13]. Organization for Economic Co-operation and Development (OECD) views the decoupling effect as a disconnection of the relationship between economic growth and environmental pressure, and distinguishes between an absolute and a relative decoupling effect [14]. Based on the OECD method, Lu et al. [15] have analyzed decoupling effects in relation to economic growth, transportation energy demands, and $\mathrm{CO}_{2}$ emissions in Germany, Japan, Korea, and Taiwan. Freitas and Kaneko [16] have examined the occurrence of a decoupling of economic growth and $\mathrm{CO}_{2}$ emissions in Brazil. Conrad and Cassar have investigated the decoupling of economic growth and environmental degradation in Malta [17]. To investigate the degree of the decoupling effect in the EU, Tapio [18] has introduced elasticity theory into the decoupling index and extended the theoretical framework of decoupling analysis. Wang et al., have examined conditions for the decoupling of the domestic extraction of materials, energy use, and sulfur dioxide $\left(\mathrm{SO}_{2}\right)$ emissions from the GDP of four selected countries [19]. Although there have been arguments about the possibility or feasibility of realizing decoupled economy and further research is needed [20-22], based on existing studies, the eco-efficiency concept and decoupling analysis can act as feasible tools to assess sustainability and provide policymakers with helpful information to design better environmental policies.

The regional scale is considered the most appropriate scale for implementing actions aimed at promoting SD [23]. In light of previous studies, we took Tianjin as our case study for evaluating sustainability trends from 2001-2013 using the eco-efficiency concept and decoupling analysis. Tianjin, which is located in China's Bohai area, is one of the four municipalities directly under the Central Government of China and is also a pilot city for developing both low-carbon and a circular economy. Tianjin is expending considerable efforts to construct an eco-city and is under pressure to come up with effective ways of achieving sustainability along with rapid industrialization and urbanization. This situation has prompted the current study. The study period is from 2001 to 2013 
which covers the following Five-Year Plans (FYPs): the tenth (2001-2005), the eleventh (2006-2010) and the first three years of the twelfth FYP (2011-2015). The city also experienced one of the highest economic growth rates. Thus, the results of this analysis will provide Tianjin's government with appropriate guidelines for formulating scientifically grounded and effective policies for the upcoming period of the thirteenth FYP in the context of ongoing economic development. They may also offer insights to other regions that are implementing initiatives for promoting sustainability.

The rest of the paper is organized as follows. Section 2 presents the research methodology and data sources, together with associated limitations. Section 3 discusses the empirical results, and Section 4 offers conclusions along with our policy recommendations.

\section{Methodology and Data Sources}

\subsection{Eco-Efficiency Analysis}

Eco-efficiency can be viewed from many perspectives. Eco-efficiency reveals the output or return that is created relative to the harm or burden that is caused [24]. According to the publication "Changing Course" of the World Business Council for Sustainable Development (WBCSD) in 1992, the term eco-efficiency envisions the production of economically-valuable goods and services while reducing the ecological impacts of production, in other words, producing more with less [25,26]. Eco-efficiency also refers to the ability of firms, industries, regions, or economies to produce more goods and services with fewer impacts on the environment and less consumption of natural resources [4]. It is often measured as a ratio of useful outputs (products and services) to environmental inputs (e.g., water consumption and energy consumption) or undesirable environmental outputs (e.g., emission of air and water pollutants). In our study, eco-efficiency was defined as follows:

$$
\text { Eco-efficiency }=\frac{\text { Economic performance }}{\text { Environmental impacts }}
$$

Economic performance was measured by real GDP at constant RMB prices (in billion Yuan) using 2000 as a base year. There are several types of environmental impact indicators with both qualitative and quantitative characteristics. Our study did not cover the qualitative aspects of sustainability such as social and cultural indicators while particular focus was given on quantitative ones which have been broadly classified into natural resource consumption indicators (e.g., fossil fuels), pressure indicators (e.g., $\mathrm{CO}_{2}$ emissions), category indicators (e.g., acidification), and total environmental impact indicators. Based on considerations of measurability, data availability and quality, and policy interests, we selected two types of eco-efficiency indicators for our study: efficiency of the resource (RE) and efficiency of the environment (EE) [2,27]. RE includes energy consumption (EC) and water resource consumption (WC). EE includes the major air pollutants, namely, $\mathrm{SO}_{2}$, fumes (including industrial dust, consistent with statistical data), and carbon dioxide $\left(\mathrm{CO}_{2}\right)$, and key water pollutants, namely, chemical oxygen demand (COD), and ammonia nitrogen (AN). These indicators directly reflect different aspects of regional environmental pressure and can be easily understood by policymakers as well as by the general public. 


\subsection{Decoupling Indices and Methods}

Whereas previous studies have predominantly focused on a single indicator of environmental impact resulting from economic growth, especially, $\mathrm{CO}_{2}$ emissions, several recent studies have examined scientific indicators of decoupling [12,28].

There are two main decoupling models for quantifying degrees of decoupling with similar applications in analyses of the decoupling relationship between environmental pressure and economic growth. The first model focuses on the decoupling factor introduced by the OECD [14] and the second, formulated by Tapio, is based on the concept of elasticity. In economics, elasticity is calculated as the ratio of the percent change in one variable to the percent change in another variable during a given time period $[18,19]$. This decoupling model is expressed by the following formula:

$$
\varepsilon=\frac{\% \Delta E}{\% \Delta G D P}=\frac{\left(E_{i} / E_{i-1}-1\right)}{\left(G D P_{i} / G D P_{i-1}-1\right)}
$$

where $\varepsilon$ denotes the decoupling elastic coefficient; $\% \Delta E$ represents the growth rate of an environmental impact (e.g., energy consumption or $\mathrm{SO}_{2}$ emission) between the end and the base period (the time interval is one year in this study); and $E_{i}$ and $E_{i-1}$ represent the environmental impact of year $i$ and year $i-1$, respectively. The $\% \triangle G D P$ denotes the growth rate of GDP from the last phase to the base period, and $G D P_{i}$ and $G D P_{i-1}$ represent the GDP of years $i$ and $i-1$, respectively. Table 1 shows eight possible decoupling states based on the decoupling elasticity value [18,29].

Coupling occurs when the decoupling elastic coefficient value falls within the range of 0.8-1.2, implying that the dependence of economic growth on environmental impacts is reinforced. Coupling can be divided into two types: expansive coupling in which both GDP and environmental impact increase and recessive coupling in which both GDP and environmental impact decrease. Negative decoupling comprises three subcategories: strong negative decoupling in which GDP decreases, environmental impacts increase, and the elastic coefficient value is negative; weak negative decoupling in which GDP and environmental impact both decrease, and the elastic coefficient value is in the range of 0-0.8; and expansive negative decoupling in which GDP and environmental impact both increase, and the elastic coefficient value is $>1.2$. Weak, strong, and recessive decoupling each denote a situation wherein the dependence of economic development on the environmental impact is declining.

Table 1. The framework for determining decoupling states.

\begin{tabular}{ccccc}
\hline & Categorization & $\boldsymbol{\varepsilon}$ & $\boldsymbol{\Delta} \boldsymbol{E}$ & $\boldsymbol{\Delta G \boldsymbol { P }}$ \\
\hline \multirow{3}{*}{ Coupling } & Expansive coupling & $0.8 \leq \varepsilon \leq 1.2$ & $>0$ & $>0$ \\
\cline { 2 - 5 } & Recessive coupling & $0.8 \leq \varepsilon \leq 1.2$ & $<0$ & $<0$ \\
\hline \multirow{3}{*}{ Negative decoupling } & Expansive negative decoupling & $\varepsilon>1.2$ & $>0$ & $>0$ \\
\cline { 2 - 5 } & Weak negative decoupling & $0 \leq \varepsilon<0.8$ & $<0$ & $<0$ \\
\cline { 2 - 5 } & Strong negative decoupling & $\boldsymbol{\varepsilon}<0$ & $>0$ & $<0$ \\
\hline \multirow{3}{*}{ Decoupling } & Recessive decoupling & $\varepsilon>1.2$ & $<0$ & $<0$ \\
\cline { 2 - 5 } & Weak decoupling & $0 \leq \varepsilon<0.8$ & $>0$ & $>0$ \\
\cline { 2 - 5 } & Strong decoupling & $\varepsilon<0$ & $<0$ & $>0$ \\
\hline
\end{tabular}


Of the eight decoupling possibilities, four may be unrealistic since negative GDP growth did not occur during the study period. Expansive coupling and expansive negative decoupling were unsatisfactory, while weak decoupling and strong decoupling were relatively acceptable.

\subsection{Data Sources}

As previously mentioned, the study period extended from 2001 to 2013 (2000 was considered the base year). This period fully covered the tenth and eleventh FYPs and part of the twelfth FYP in China. We adopted the GDP measure, cited in the Tianjin Statistical Yearbook 2014 [30] in billion Yuan at a constant RMB price for the base year 2000, for our economic data. The data on energy consumption were compiled from the energy balance table provided in the China Energy Statistical Yearbook [31] in units of 10,000 tons of coal equivalents (TCE). We estimated $\mathrm{CO}_{2}$ emissions associated with the ultimate energy consumption of coal, coke, natural gas, liquefied petroleum gas, crude oil, gasoline, kerosene, diesel, and fuel oil relating to primary, secondary, and tertiary industries as well as residential consumption during the study period. Estimations were calculated by applying the approach proposed in the 2006 IPCC Guidelines for National Greenhouse Gas Inventories [32]. All other data were extracted from China's official national statistics. All of the computations were performed using the Microsoft Excel application.

\section{Results and Discussion}

During the study period (2001-2013), the annual growth rate was $14.9 \%$ which was much higher than the national average. Tianjin's GDP increased from 190.6 billion RMB to 1032.2 billion RMB (based on the constant price in 2000) [30]. Despite the adoption of a number of energy-saving measures, energy consumption, in concert with ongoing industrialization and urbanization processes, has shown an annual increase from 29.18 million TCE in 2001 to 88.23 million TCE in 2013. However, Tianjin's annual water consumption showed little change. The average volume consumed was about 2193.7 million cubic meters per year, with an annual variation of $\pm 9 \%$. From 2001 to 2013, the absolute quantities of discharged fumes, $\mathrm{COD}$, and ammonia nitrogen (AN) decreased by factors of 0.56, 0.62, and 0.39, respectively. Conversely, the absolute quantities of $\mathrm{SO}_{2}$ and $\mathrm{CO}_{2}$ discharged increased by factors of 1.084 and 2.01, respectively. Figure 1 presents a comparison of the annual GDP value in relation to each of the selected indicators of environmental pressure (e.g., energy consumption, $\mathrm{CO}_{2}$ emissions, and $\mathrm{COD}$ emissions) based on a relative scale. That is, the value obtained for each indicator was divided by the corresponding value in 2001 , as the reference year, and the results were multiplied by 100 , thus enabling the inclusion of indicators with different units or magnitudes within the same figure.

We used the methods described in Section 2 to examine eco-efficiency trends and levels of decoupling of environmental pressures from economic growth in Tianjin during the period from 2001-2013. The results obtained are presented below. 


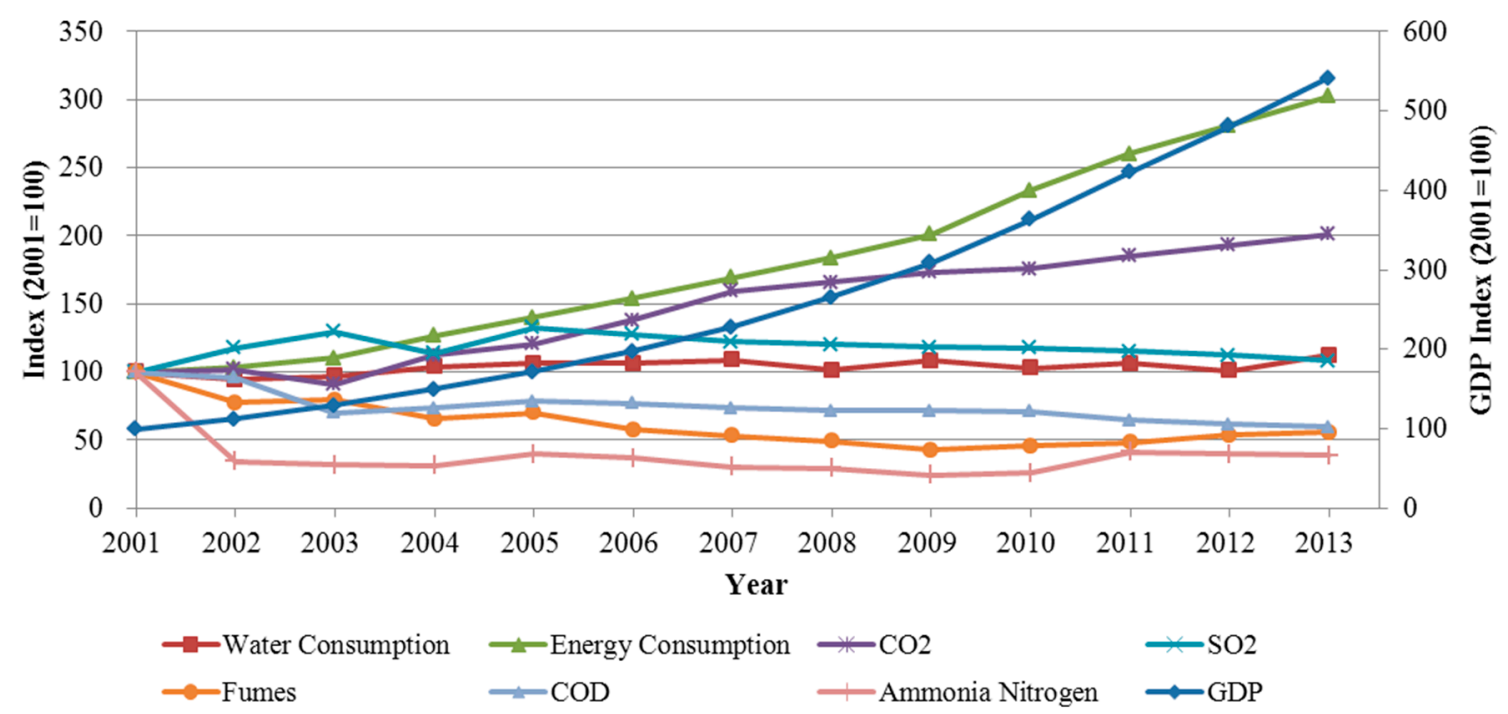

Figure 1. Trends for $\mathrm{WC}, \mathrm{EC}, \mathrm{CO}_{2}, \mathrm{SO}_{2}$, fumes, $\mathrm{COD}$, and $\mathrm{AN}$ emissions in Tianjin in relation to GDP from 2001-2013.

\subsection{Eco-Efficiency Trends Analysis}

As shown in Table 2, all of the eco-efficiency indicators in Tianjin improved during the study period. The most notable improvements occurred for fumes associated with air pollutant emissions and for AN among water pollutant emissions.

Table 2. Results of the eco-efficiency evaluation for Tianjin from 2001-2013.

\begin{tabular}{cccccccc}
\hline & $\mathbf{W C}^{\mathbf{a}}$ & $\mathbf{E C}^{\mathbf{b}}$ & $\mathbf{C O}_{\mathbf{2}}{ }^{\mathbf{c}}$ & $\mathbf{S O}_{\mathbf{2}}{ }^{\mathbf{d}}$ & Fumes $^{\mathbf{d}}$ & $\mathbf{C O D}^{\mathbf{d}}$ & $\mathbf{A N}^{\mathbf{d}}$ \\
\hline 2001 & 90.2 & 6532.1 & 5061.2 & 95.3 & 121.6 & 102.4 & 387.4 \\
2002 & 107.6 & 7108.1 & 5613.3 & 91.4 & 176.5 & 120.0 & 1263.8 \\
2003 & 120.2 & 7670.7 & 7216.3 & 95.1 & 197.9 & 189.1 & 1567.6 \\
2004 & 130.0 & 7725.2 & 6742.6 & 125.3 & 277.3 & 208.4 & 1851.1 \\
2005 & 145.7 & 8033.3 & 7210.6 & 123.8 & 298.3 & 224.6 & 1674.3 \\
2006 & 167.3 & 8363.3 & 7239.1 & 147.6 & 418.2 & 263.2 & 2070.2 \\
2007 & 188.9 & 8794.5 & 7235.3 & 177.6 & 523.7 & 316.6 & 2914.3 \\
2008 & 236.3 & 9441.9 & 8104.4 & 210.9 & 657.7 & 380.5 & 3531.5 \\
2009 & 257.4 & $10,043.8$ & 9035.4 & 249.3 & 880.6 & 443.6 & 4924.7 \\
2010 & 318.8 & $10,158.9$ & $10,444.3$ & 294.6 & 963.1 & 524.7 & 5401.1 \\
2011 & 359.0 & $10,610.5$ & $11,540.0$ & 349.2 & 1061.9 & 667.9 & 3955.8 \\
2012 & 430.9 & $11,178.0$ & $12,606.5$ & 408.6 & 1091.5 & 796.8 & 4698.1 \\
2013 & 434.5 & $11,698.5$ & $13,616.6$ & 476.0 & 1180.2 & 929.0 & 5397.9 \\
\hline
\end{tabular}

${ }^{\mathrm{a}}$ Unit: Yuan $/ \mathrm{m}^{3}$; ${ }^{\mathrm{b}}$ Unit: Yuan/TCE; ${ }^{\mathrm{c}}$ Unit: Yuan/ton; ${ }^{\mathrm{d}}$ Unit: $10^{4}$ Yuan/ton.

\subsubsection{An Analysis of the Eco-Efficiency of Resource}

As shown in Figure 2, the eco-efficiency of WC increased annually during the study period at an average annual growth rate of $14.2 \%$ (a factor of 4.82) from 90.2 to $434.5 \mathrm{Yuan} / \mathrm{m}^{3}$. This indicated an absolute advantage compared with the eco-efficiency of WC in other Chinese provinces during the same period [33]. On the one hand, this improvement could be attributed to the much higher growth 
rate of GDP (see Figure 1). On the other hand, a series of water-saving measures ensured the volume of water consumed remained stable. These included improving the recycling rate of industrial water, reducing leakage of water from the network of supply pipes, and enhancing agricultural irrigation efficiency.

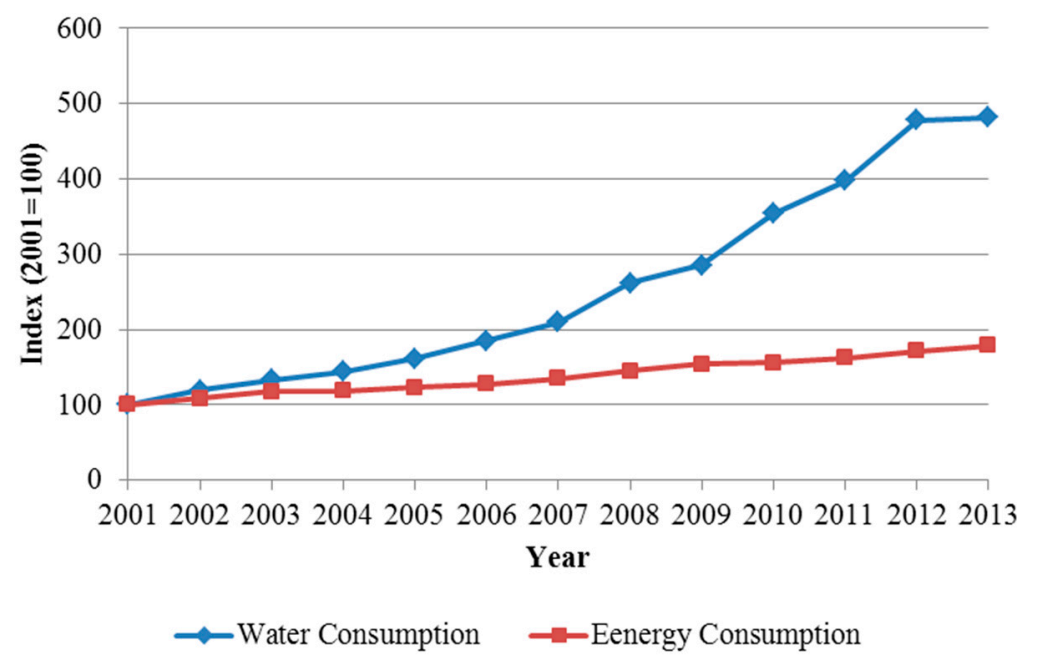

Figure 2. Eco-efficiency trends for water and energy consumption in Tianjin from 2001-2013.

The eco-efficiency of EC indicates how much GDP can be produced from the use of one unit of energy, providing a good measure of an economy's energy efficiency. This, too, showed an annual increase (see Figure 2), from 6532.1 to 11,698.5 Yuan/TCE, with a smaller average annual growth rate of $5.0 \%$. This improvement was a result of energy efficiency improvement and energy saving. Although the energy-saving target of increasing eco-efficiency of energy consumption by $25 \%$, as stipulated in the eleventh FYP, were exceeded (a 26.5\% increment has been achieved), the eco-efficiency of Tianjin remained lower than that of Beijing and Shanghai for the same period. Thus, for example, the eco-efficiency values of EC in Beijing and Shanghai in 2013 were 18,958.5 Yuan/TCE and 15,252.1 Yuan/TCE, respectively. Since structural effects may affect energy consumption to some degree [34], the gap in the eco-efficiency of EC between Tianjin, Beijing, and Shanghai can be explained from the perspective of differences in the industrial structures of these cities. Taking 2010 as an example, the share of primary, secondary, and tertiary industries in Tianjin was $1.6 \%, 52.4 \%$, and $46.0 \%$, respectively. These figures differed significantly from those for Beijing $(0.9 \%, 24.0 \%$, and $75.0 \%$, respectively) and for Shanghai $(0.7 \%, 42.0 \%$, and $57.3 \%$, respectively). Evidently, secondary industry remained dominant in Tianjin, with high consumption of energy by key industries such as smelting and pressing of metals and manufacture of chemical materials and products. Concurrently, the development of a modern service industry in Tianjin is lagging behind.

\subsubsection{An Eco-Efficiency Analysis of the Environment}

The actions of central and local governments reflect the fact that reduction of pollutant emissions is a primary objective aimed at achieving sustainability. There have been significant achievements in this area resulting from the implementation of a number of measures during earlier previous FYPs [35,36]. These include optimization and adjustment of energy and industrial structures to reduce emissions (structure emission reduction), implementation of key energy-saving emission reduction projects 
(project emission reduction), emissions reduction management in key industries (management emission reduction), technology development and application, eco-industrial park construction, and circular economy development.

Eco-efficiency relating to emission of air pollutants, namely, $\mathrm{CO}_{2}, \mathrm{SO}_{2}$, and fumes all increased during the study period as shown in Figure 3. The most significant increase in eco-efficiency was observed for fumes which rose by a factor of 9.70. Conversely, the slowest increase was observed for $\mathrm{CO}_{2}$ which rose by a factor of 2.69 because of the rapid growth rate of $\mathrm{CO}_{2}$ emission at 38.14 million tons of emission increment, with an annual average increase rate of $6.0 \%$. The eco-efficiency of $\mathrm{SO}_{2}$ rose by a factor of 4.99 .

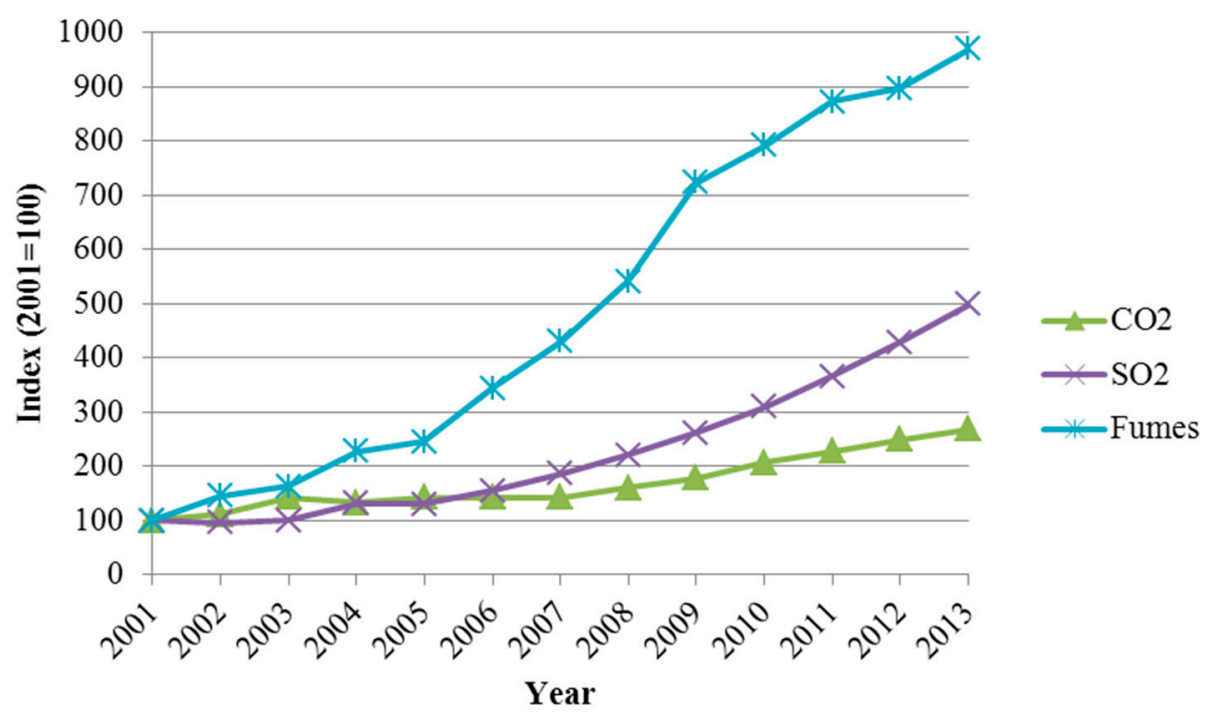

Figure 3. Eco-efficiency trends for air pollution emissions in Tianjin from 2001-2013.

Carbon intensity is defined as the ratio of $\mathrm{CO}_{2}$ emission to GDP which is the reciprocal value of the eco-efficiency of $\mathrm{CO}_{2}$. According to our calculations, Tianjin's carbon intensity was about 0.793 ton/10,000 Yuan in 2012 (i.e., 10,444.3 Yuan/ton, at a constant price for 2000). This value was higher than the overall value for China in 2012 (2.436 ton/10,000 Yuan, based on the constant price for 2000), calculated by Yu et al. [37]. During the 12th FYP period (2011-2015), the Tianjin government proclaimed a quantitative target of a $19 \%$ reduction in carbon emission intensity [38]. Several factors can affect energy-related $\mathrm{CO}_{2}$ emissions, such as economic development, energy intensity, industrial structure, and the ultimate energy consumption structure $[28,39]$. In line with the changing trend that has been evident from 2011, fulfillment of the established target should be feasible.

The reduction in $\mathrm{SO}_{2}$ emissions contributed to enhancing the rise in eco-efficiency. Over the duration of the tenth, eleventh, and twelfth FYPs, $\mathrm{SO}_{2}$ has remained one of the targeted pollutants for emissions reduction. The amount of $\mathrm{SO}_{2}$ discharged peaked in 2005 at 0.265 million tons, fulfilling the goal of a $20 \%$ decrease in relation to emissions in 2000. In 2010, the amount of $\mathrm{SO}_{2}$ discharged was 0.235 million tons, indicating that the goal of a $10 \%$ decrease in relation to the 2005 emissions had been achieved. The Tianjin Municipal Environmental Protection Bureau announced a 9.4\% $\mathrm{SO}_{2}$ emissions reduction goal for 2011-2015 during “The 12th Five-Year Plan for Tianjin's environmental protection". Although Tianjin has made remarkable progress in relation to $\mathrm{SO}_{2}$ eco-efficiency, there is still room for further improvement when compared with Beijing and Shanghai. For example, the $\mathrm{SO}_{2}$ 
eco-efficiency values of Beijing and Shanghai in 2013 were $1602.6 \times 10^{4}$ Yuan/ton and $827.2 \times 10^{4}$ Yuan/ton, respectively. These values exceeded those of Tianjin $\left(476.0 \times 10^{4}\right.$ Yuan/ton $)$ as well as Chongqing $\left(166.8 \times 10^{4}\right.$ Yuan/ton $)$.

The eco-efficiency of fumes in Tianjin increased annually at an average annual rate of $21.7 \%$ from $121.6 \times 10^{4}$ Yuan/ton to $1180.2 \times 10^{4}$ Yuan/ton from 2001-2013. This situation was better than that of Chongqing, but not as good as the eco-efficiency increases for Beijing and Shanghai. For instance, in 2013, the eco-efficiency values for fumes in Beijing, Shanghai, and Chongqing were $2351.2 \times 10^{4} \mathrm{Yuan} /$ ton, $2206.5 \times 10^{4}$ Yuan/ton, and 508.2 $\times 10^{4} \mathrm{Yuan} /$ ton, respectively.

In the case of water pollution, discharge of COD and its eco-efficiency improved at an annual rate of $-3.8 \%$ and $20.7 \%$, respectively (see Figure 4 ). These values are lower than the corresponding measures for AN which indicate improvements in discharge and the eco-efficiency indicator at annual rates of $-2.8 \%$ and $33.4 \%$, respectively (see Figure 4 ).

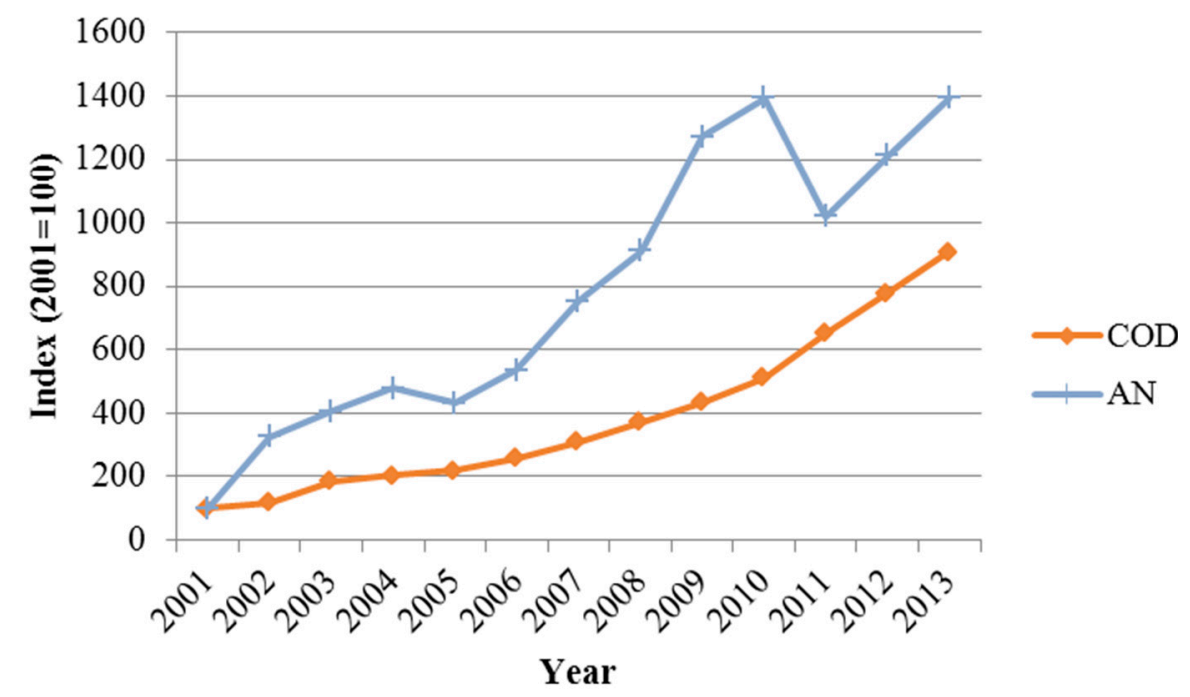

Figure 4. Eco-efficiency trends for emission of water pollutants in Tianjin from 2001-2013.

During the study period, COD was also one of the targeted pollutants for emissions reduction, while AN was only included during the periods of the tenth and twelfth FYPs. The amounts of COD discharged in 2005 and 2010 were 0.146 million tons and 0.132 million tons, respectively. Both amounts indicated fulfillment of the goal of a 10\% decrease for the tenth and eleventh FYP periods. The above reduction can be primarily attributed to project emission reduction which has greatly improved the sewage treatment rate. The Tianjin Municipal Environmental Protection Bureau declared emission reduction goals of 9.2\% and 10.4\% for COD and AN, respectively, from 2011 to 2015 in "The 12th Five-Year Plan for Tianjin's environmental protection". The reduction of pollutant emissions has contributed to enhancing their eco-efficiency.

Of municipalities under the direct jurisdiction of the Central Government, Tianjin's COD eco-efficiency was the highest at $929.0 \times 10^{4}$ Yuan/ton in 2013. The corresponding COD eco-efficiency values of Beijing, Shanghai, and Chongqing were $782.4 \times 10^{4}$ Yuan/ton, $899.3 \times 10^{4} \mathrm{Yuan} /$ ton, and $338.3 \times 10^{4} \mathrm{Yuan} /$ ton, respectively. Tianjin ranked in second place for AN eco-efficiency. The AN eco-efficiency of Beijing, Tianjin, Shanghai, and Chongqing were $7077.4 \times 10^{4}$ Yuan/ton, 5397.9 $\times 10^{4}$ Yuan/ton, $4299.9 \times 10^{4}$ Yuan/ton, and $2313.2 \times 10^{4}$ Yuan/ton, respectively. 
Although all of the eco-efficiency indicators that we analyzed for Tianjin improved during the study period - and have, to some extent, contributed to measurements of the city's sustainability - the question of how to further improve eco-efficiency remains.

\subsection{Decoupling Analysis}

Table 3 shows states of environmental impact decoupling from economic growth for the period 2001-2013. These results provide a number of insights as discussed below.

Table 3. Results of decoupling analysis for Tianjin from 2001 to 2013.

\begin{tabular}{lccccccc}
\hline & Water & Energy & $\mathbf{C O}_{2}$ & SO $_{2}$ & Fumes & COD & AN \\
\hline 2001 & WD & WD & SD & SD & SD & WD & EN \\
2002 & SD & WD & WD & EN & SD & SD & SD \\
2003 & WD & WD & SD & WD & WD & SD & SD \\
2004 & WD & EC & EN & SD & SD & WD & SD \\
2005 & WD & WD & WD & EC & WD & WD & EN \\
2006 & SD & WD & EC & SD & SD & SD & SD \\
2007 & WD & WD & EC & SD & SD & SD & SD \\
2008 & SD & WD & WD & SD & SD & SD & SD \\
2009 & WD & WD & WD & SD & SD & SD & SD \\
2010 & SD & EC & WD & SD & WD & SD & WD \\
2011 & WD & WD & WD & SD & WD & SD & EN \\
2012 & SD & WD & WD & SD & WD & SD & SD \\
2013 & EC & WD & WD & SD & WD & SD & SD \\
\hline
\end{tabular}

WD: weak decoupling; SD: strong decoupling; EC: expansive coupling; EN: expansive negative decoupling.

\subsubsection{Water and Energy Consumption}

As is evident from the first column of Table 3, decoupling effects for water consumption and economic growth were weak, as well as strong, for most of the years of our study period. However, the expansive coupling state that occurred in 2013 serves as a warning signal of overconsumption of water. Figure 5, which shows the growth rates of GDP, WC, and EC from 2001-2013, indicates that the growth rate of GDP peaked at $17.4 \%$ in 2010 , subsequently declining to reach $12.5 \%$ in 2013 . However, the growth rate of WC fluctuated during the study period and peaked at $11.6 \%$ in 2013 .

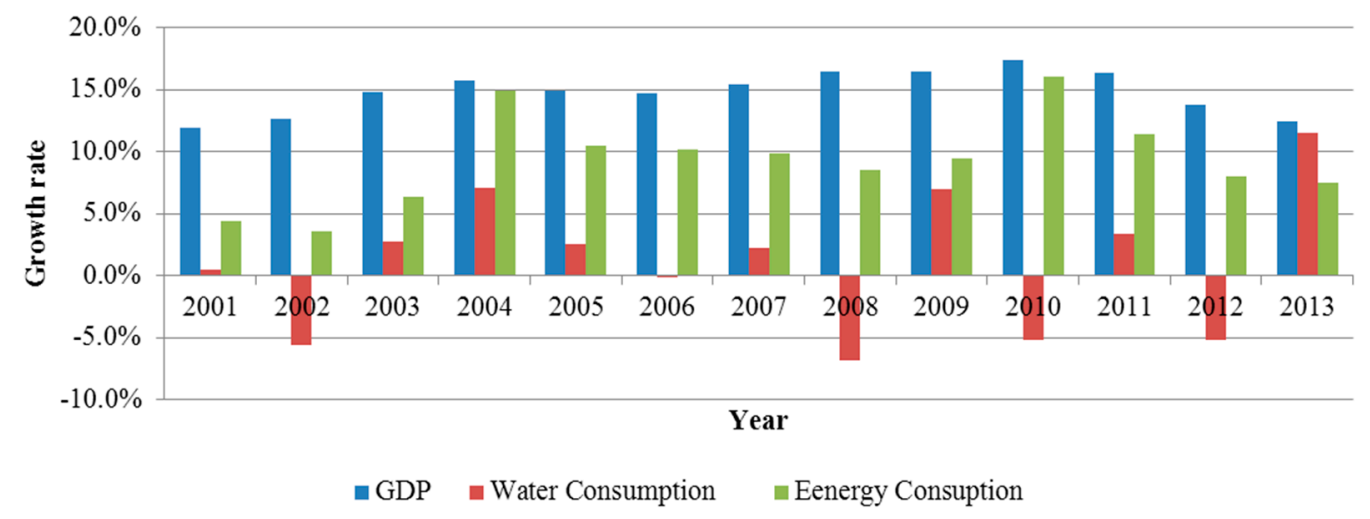

Figure 5. Growth rates of GDP, WC, and EC in Tianjin from 2001-2013. 
From 2001 to 2013, with increasing energy consumption corresponding to the fast pace of economic growth, decoupling of energy consumption and economic growth was characteristically weak. This indicated that although annual energy consumption continued to rise during this period, energy efficiency was evidently enhanced, and the increase in consumption lagged behind the pace of economic growth for most of this period. An expansive coupling effect occurred in 2004 and 2010 which can be attributed to the fast pace of growth of EC during these two years, as shown in Figure 5.

\subsubsection{Emissions of Air and Water Pollutants}

The fourth column of Table 3 indicates that there was a strong decoupling effect (eight out of 13 states) and a weak decoupling effect (two out of 13 states) for $\mathrm{CO}_{2}$ emissions and economic growth in Tianjin during most of the years from 2001-2013. This is consistent with the results of a decoupling study conducted at the provincial level of China [29]. There was also an expansive coupling effect during two years (2006 and 2007) and an expansive negative decoupling effect in 2004. In 2007 the decoupling elasticity reached its peak at 1.01, implying that the increasing rate of carbon emissions almost equaled that of the GDP, as shown in Figure 6. This fast pace of growth of $\mathrm{CO}_{2}$ emissions was brought under control from 2008 onward, evidenced by a considerable decline in decoupling elasticity from 2008-2013. This trend indicated a much slower pace of $\mathrm{CO}_{2}$ emissions compared with that of the GDP. Furthermore, the large proportion of the weak decoupling effect implies that although there has been some progress relating to the control of $\mathrm{CO}_{2}$ emissions, there is an urgent requirement for a variety of policies to direct the current phase toward strong decoupling. Therefore, to break the connection between $\mathrm{CO}_{2}$ emissions and economic growth, and to achieve Tianjin's carbon emission intensity target (a decrease of 19\% from 2010 to 2015), the government will need to introduce further effective measures.

Tianjin achieved a strong decoupling effect for $\mathrm{SO}_{2}$ emissions during the latter half of the study period from 2006-2013 (including the period of the 11th FYP and the first three years of the twelfth FYP). Additionally, weak decoupling was evident in 2003, while expansive negative decoupling and expansive coupling occurred in 2002 and 2005, respectively, mainly as a result of the relatively high $\mathrm{SO}_{2}$ emission growth rate during these two years (see Figure 6).

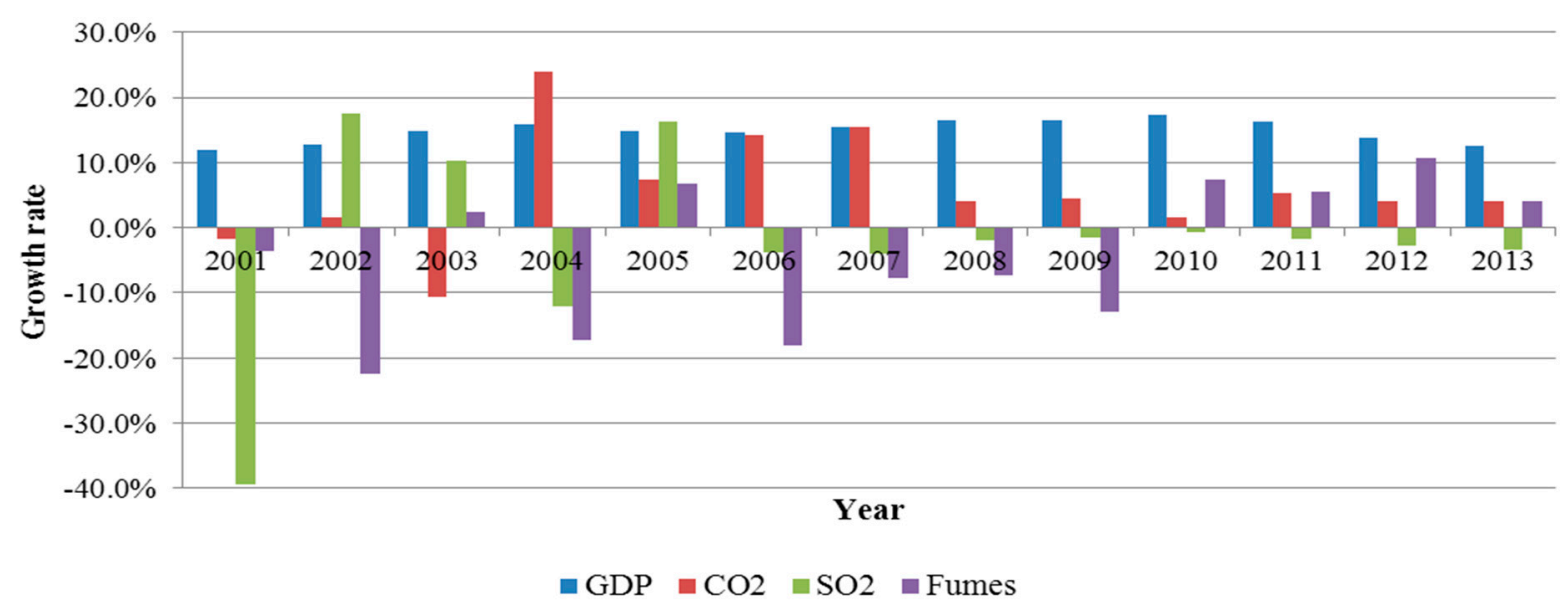

Figure 6. Growth rates of GDP, $\mathrm{CO}_{2}, \mathrm{SO}_{2}$, and fumes in Tianjin from 2001-2013. 
During the study period, decoupling effects for emissions of fumes were mainly strong and weak. However, excessive volatility of the growth rate for fumes caused the decoupling state to become complex (see Figure 6).

In general, COD emissions alternated between strong and weak decoupling states during the study period. They revealed an apparent overall tendency toward strong decoupling. In 2001, a shift occurred from weak decoupling to strong decoupling, with the latter prevailing during 2002 and 2003. This was followed by a period of short-term volatility in 2004 and 2005 (weak decoupling) and, subsequently, by a sustained period of strong decoupling during 2006-2013.

The elasticity values for AN varied a great deal during the study period. Strong decoupling effects for AN emissions and economic growth occurred during most years. Additionally, expansive coupling occurred in 2001, 2005, and 2011 because of the fast pace of increase of emissions during these years (see Figure 7) and the weak decoupling that occurred in 2010.

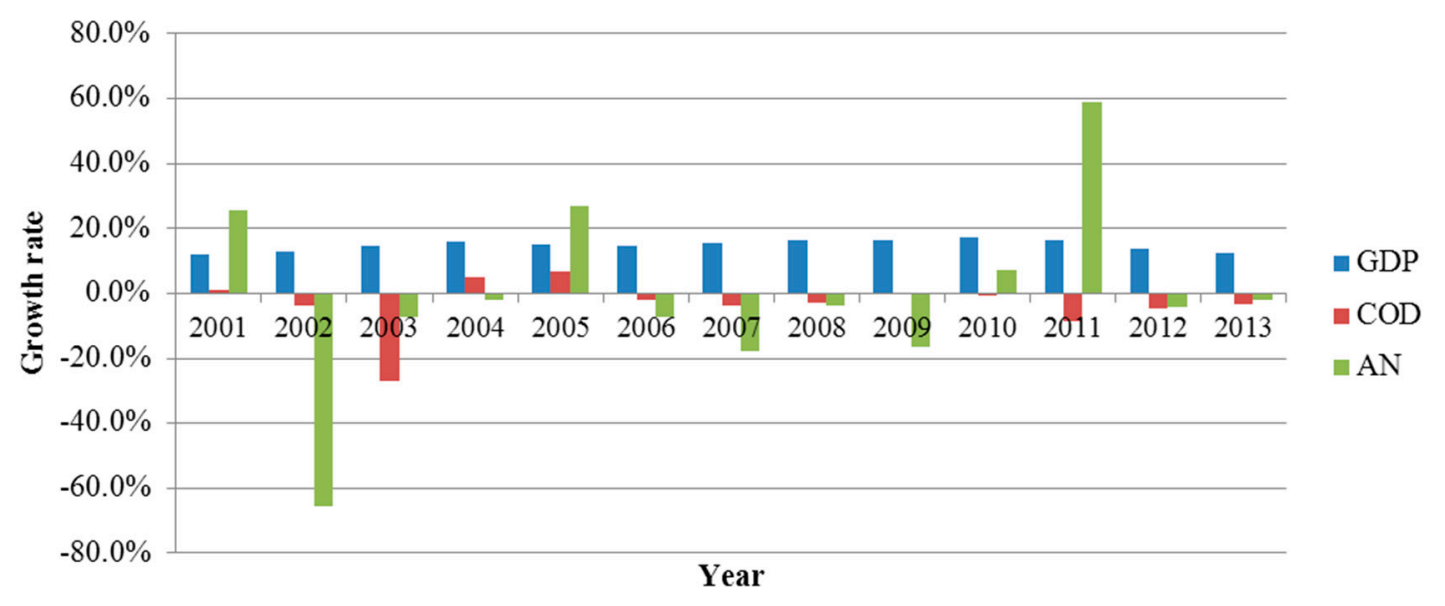

Figure 7. Growth rates of GDP, COD, and AN in Tianjin from 2001-2013.

\section{Conclusions and Policy Recommendations}

In this paper, we have analyzed Tianjin's eco-efficiency trends and the decoupling relationship between environmental pressure and economic growth from 2001 to 2013 . This study is aimed at seeking efficient ways of achieving sustainability in Tianjin. Several conclusions follow from our findings.

The eco-efficiency of all of the indicators analyzed for Tianjin improved during the study period, and Tianjin made significant progress in reducing its emissions of air and water pollutants. The one exception was $\mathrm{CO}_{2}$, with a continual increase in the discharge amount and, conversely, a continual decrease in $\mathrm{CO}_{2}$ intensity. Notwithstanding these improvements, promotion of resource efficiency should be accorded high priority in the long run, because there is still an evident gap in Tianjin's eco-efficiency levels compared with those at the domestic and international scales.

Our decoupling analysis has demonstrated that some progress has been made in decoupling GDP growth from environmental pressure in Tianjin. This can be attributed to the implementation of existing policies and measures entailing resource conservation and reduction in the emission of pollutants, especially $\mathrm{SO}_{2}$ and $\mathrm{COD}$, which both retained strong decoupling states after 2006. Other indicators have shown an apparent tendency toward decoupling, but this decoupling has been weak, mainly, emphasizing the need for further concerted efforts to promote a shift to strong decoupling. 
To sum up, although some achievements relating to sustainability have been evident in Tianjin, challenges remain and require appropriate responses. Based on the empirical analyses that we have presented in this paper, we offer the following policy recommendations. These can be taken up by the Tianjin government, subsequent to the completion of the twelfth FYP, and incorporated into the thirteenth FYP to promote sustainable development.

(1) Resource consumption. At the current juncture, improvement in resource consumption efficiency should be prioritized. The administration is expected to continue its efforts to strengthen water saving, seawater desalination, and renewable water recycling. These are accomplished through the implementation of mandatory measures (e.g., setting water consumption quota standards for industries with high water consumption), introduced in parallel with practicable financial incentives (e.g., stepped water price system). Industrial structural adjustments, low carbonization, and technological innovations will result in further improvements in the comprehensive efficiency of energy consumption.

(2) Reductions in the emission of pollutants. We would advise the administration to significantly enhance structure emission reduction and management emission reduction. This is because existing achievements in emission reduction can be mainly attributed to the installation and operation of emission reduction projects. However, in recent years, the potential for project emission reduction has significantly decreased. In order to reduce emissions of air pollutants, so as to improve ambient air quality, the administration needs to expand the use ratio of natural gas and other clean energy, speed up the construction of non-coal-fired areas, promote the usage of clean coal in rural areas, prohibit straw burning and put forward its comprehensive utilization, and enhance emissions reduction of VOCs and $\mathrm{NH}_{3}$ in the near future. In the meantime, the promotion of clean aquaculture and ecological livestock breeding, the improvement of rural sewage treatment, and the pollution load reduction of planting industry need to be strengthened. We further recommend that the administration gives full consideration to the co-benefits of simultaneously reducing the emissions of various pollutants, for example, by controlling localized air pollutants, such as $\mathrm{SO}_{2}$ and reducing $\mathrm{CO}_{2}$ emission per unit of GDP, with the aim of cutting costs.

This study has explored the eco-efficiency of only seven indicators, and its assessment of the decoupling status of Tianjin has been limited by data availability. A possible extension of this study would be to further compare the eco-efficiencies and environmental performances of different regions in China to uncover the underlying reasons behind these differences over time.

\section{Author Contributions}

Lin Zhao and Zhe Wang designed research; Lin Zhao, Zhe Wang, Guozhu Mao and Ben Wu performed research. All authors wrote the paper. All authors have read and approved the final manuscript.

\section{Conflicts of Interest}

The authors declare no conflict of interest. 


\section{References}

1. Ehrenfeld, J.R. Eco-efficiency-Philosophy, theory, and tools. J. Ind. Ecol. 2005, 9, 6-8.

2. Seppala, J.; Melanen, M.; Maenpaa, I.; Koskela, S.; Tenhunen, J.; Hiltunen, M.R. How can the eco-efficiency of a region be measured and monitored? J. Ind. Ecol. 2005, 9, 117-130.

3. Dagiliute, R.; Juknys, R. Eco-efficiency: Trends, goals and their implementation in Lithuania. J. Environ. Eng. Landsc. Manag. 2012, 20, 265-272.

4. Camarero, M.; Castillo, J.; Picazo-Tadeo, A.J.; Tamarit, C. Eco-efficiency and convergence in OECD countries. Environ. Resour. Econ. 2013, 55, 87-106.

5. Yu, Y.D.; Chen, D.J.; Zhu, B.; Hu, S.Y. Eco-efficiency trends in china, 1978-2010: Decoupling environmental pressure from economic growth. Ecol. Indic. 2013, 24, 177-184.

6. Burritt, R.L.; Saka, C. Environmental management accounting applications. And eco-efficiency: Case studies from Japan. J. Clean. Prod. 2006, 14, 1262-1275.

7. Wang, Y.; Liu, J.; Hansson, L.; Zhang, K.; Wang, R. Implementing stricter environmental regulation to enhance eco-efficiency and sustainability: A case study of Shandong Province's pulp and paper industry, China. J. Clean. Prod. 2011, 19, 303-310.

8. Jevons, W.S. The Coal Question: An Inquiry Concerning the Progress of the Nation, and the Probable Exhaustion of Our Coal-Mines; Macmillan: London, UK, 1906.

9. Alcott, B. Jevons' paradox. Ecol. Econ. 2005, 54, 9-21.

10. Frye-Levine, L.A. Sustainability through design science: Re-imagining option spaces beyond eco-efficiency. Sustain. Dev. 2012, 20, 166-179.

11. Yin, K.; Wang, R.S.; An, Q.X.; Yao, L.; Liang, J. Using eco-efficiency as an indicator for sustainable urban development: A case study of Chinese provincial capital cities. Ecol. Indic. 2014, $36,665-671$.

12. Wang, Z.H.; Yang, L. Delinking indicators on regional industry development and carbon emissions: Beijing-Tianjin-Hebei economic band case. Ecol. Indic. 2015, 48, 41-48.

13. Zhang, Z.; Chen, X.; Heck, P.; Xue, B.; Liu, Y. Empirical study on the environmental pressure versus economic growth in China during 1991-2012. Resour. Conserv. Recycl. 2015, 101, 182-193.

14. OECD. Indicators to Measure Decoupling of Environmental Pressures from Economic Growth; OECD: Paris, France, 2002.

15. Lu, I.J.; Lin, S.J.; Lewis, C. Decomposition and decoupling effects of carbon dioxide emission from highway transportation in Taiwan, Germany, Japan and South Korea. Energy Policy 2007, $35,3226-3235$.

16. De Freitas, L.C.; Kaneko, S. Decomposing the decoupling of $\mathrm{CO}_{2}$ emissions and economic growth in Brazil. Ecol. Econ. 2011, 70, 1459-1469.

17. Conrad, E.; Cassar, L. Decoupling economic growth and environmental degradation: Reviewing progress to date in the small island state of Malta. Sustainability 2014, 6, 6729-6750.

18. Tapio, P. Towards a theory of decoupling: Degrees of decoupling in the EU and the case of road traffic in Finland between 1970 and 2001. Transp. Policy 2005, 12, 137-151.

19. Wang, H.M.; Hashimoto, S.; Yue, Q.; Moriguchi, Y.; Lu, Z.W. Decoupling analysis of four selected countries: China, Russia, Japan, and the United States during 2000-2007. J. Ind. Ecol. 2013, 17, 618-629. 
20. Nicholas, G.-R. The Entropy Law and Economic Process; Harvard University Press: Cambridge, MA, USA, 2014.

21. Jackson, T. Prosperity without Growth?: The Transition to a Sustainable Economy: [Summary]. Available online: https://research-repository.st-andrews.ac.uk/handle/10023/2165 (accessed on 17 November 2015).

22. Kallis, G. In defence of degrowth. Ecol. Econ. 2011, 70, 873-880.

23. Coelho, P.; Mascarenhas, A.; Vaz, P.; Dores, A.; Ramos, T.B. A framework for regional sustainability assessment: Developing indicators for a Portuguese region. Sustain. Dev. 2010, 18, 211-219.

24. Figge, F.; Young, W.; Barkemeyer, R. Sufficiency or efficiency to achieve lower resource consumption and emissions? The role of the rebound effect. J. Clean. Prod. 2014, 69, 216-224.

25. Schmidheiny, S. Changing Course: A Global Business Perspective on Development and the Environment; MIT Press: Cambridge, MA, USA, 1992; Volume 1.

26. Carrillo-Hermosilla, J.; Río González, P.D.; Könnölä, T. Eco-Innovation: When Sustainability and Competitiveness Shake Hands; Palgrave: London, UK, 2009.

27. Wang, Y.; Sun, M.; Wang, R.; Lou, F. Promoting regional sustainability by eco-province construction in China: A critical assessment. Ecol. Indic. 2015, 51, 127-138.

28. Zhang, Y.J.; Da, Y.B. The decomposition of energy-related carbon emission and its decoupling with economic growth in China. Renew. Sustain. Energy Rev. 2015, 41, 1255-1266.

29. Song, Y.; Zhang, M.; Dai, S. Study on China's energy-related $\mathrm{CO}_{2}$ emission at provincial level. Nat. Hazards 2015, 77, 89-100.

30. Tianjin Municipal Bureau of Statistics. Tianjin Statistical Yearbook 2014; China Statistics Press: Beijing, China, 2014.

31. National Bureau of Statistics of China. China Energy Statistical Yearbook; China Statistics Press: Beijing, China, 2001-2014.

32. IPCC. 2006 IPCC Guidelines for National Greenhouse Gas Inventories[db/ol]. Available online: http://www.ipcc-nggip.iges.or.jp/public/2006gl/index.html (accessed on 18 September 2015).

33. National Bureau of Statistics of China. China Statistical Yearbook 2014; China Statistics Press: Beijng, China, 2014.

34. Fernandez Gonzalez, P.; Landajo, M.; Presno, M.J. Multilevel lmdi decomposition of changes in aggregate energy consumption. A cross country analysis in the EU-27. Energy Policy 2014, 68, $576-584$.

35. Xue, B.; Mitchell, B.; Geng, Y.; Ren, W.X.; Muller, K.; Ma, Z.X.; de Oliveira, J.A.P.; Fujita, T.; Tobias, M. A review on China's pollutant emissions reduction assessment. Ecol. Indic. 2014, 38, 272-278.

36. Price, L.; Levine, M.D.; Zhou, N.; Fridley, D.; Aden, N.; Lu, H.Y.; McNeil, M.; Zheng, N.N.; Qin, Y.N.; Yowargana, P. Assessment of China's energy-saving and emission-reduction accomplishments and opportunities during the 11th five year plan. Energy Policy 2011, 39, 2165-2178.

37. Yu, S.; Zhang, J.; Zheng, S.; Sun, H. Provincial carbon intensity abatement potential estimation in China: A pso-ga-optimized multi-factor environmental learning curve method. Energy Policy 2015, 77, 46-55. 
38. The State Council. Work Plan for Controlling Greenhouse Gas Emissions for the Twelfth Five-Year Plan; The State Council: Beijng, China, 2011.

39. Wang, Z.; Zhao, L.; Mao, G.; Wu, B. Factor decomposition analysis of energy-related $\mathrm{CO}_{2}$ emissions in Tianjin, China. Sustainability 2015, 7, 9973-9988.

(C) 2015 by the authors; licensee MDPI, Basel, Switzerland. This article is an open access article distributed under the terms and conditions of the Creative Commons Attribution license (http://creativecommons.org/licenses/by/4.0/). 